\title{
Hypertension in an Adult with Unilateral Renal Dysplasia
}

\author{
Osahiko Sunagawa, Tanenao Eto, Yasuhiro Noda, Koshiro FukiYama and Akira Kusaba*
}

\begin{abstract}
We report a 29-year-old Japanese female with severe hypertension and unilateral renal dysplasia, which is rarely found in adults. The involved kidney was surgically removed and then the blood pressure fell to borderline levels without any changes in plasma renin activity or plasma aldosterone concentration. Histological examinations revealed typical renal dysplasia without hyperplasia of the juxtaglomerular apparatus. Unilateral renal dysplasia may be a cause of secondary hypertension in adults, though the mechanisms are still unknown.

(Internal Medicine 31: 530-533, 1992)
\end{abstract}

Key words: kidney, blood pressure, plasma renin activity

\section{Introduction}

Renal dysplasia is a congenital underdevelopment or developmental arrest of the renal parenchyma $(1,2)$. Several reports have discussed hypertension in adults with unilateral renal dysplasia (3-5). Removal of the affected kidney rarely reduces blood pressure $(3,5,6)$. We described here an adult patient with severe hypertension and unilateral renal dysplasia in whom blood pressure was reduced by unilateral nephrectomy.

\section{Case Report}

A 29-year-old Japanese woman was admitted to our hospital in July 1986, complaining of hypertension. No remarkable abnormalities had been observed in her growth or development. Her blood pressure remained normotensive during the each gestation period in 1976, 1978, and 1980. Since 1981, she had experienced acute urinary tract infection several times, and each infection had easily been treated with antibiotics. In 1982, at age 25 , hypertension was found and treatment was started at another clinic. However, her blood pressure was inadequately controlled with antihypertensive agents because of poor compliance. On admission, physical examination revealed a blood pressure of $184 / 116 \mathrm{mmHg}$ in the sitting position, a diffuse goiter in the neck, and a bruit audible in the left upper area of the abdomen. No cardiomegaly was found. The ocular fundi showed a grade 1 hypertensive retinopathy. Neither peripheral edema nor neurologic abnormalities were noted.

The laboratory investigations disclosed hemoglobin of $14.6 \mathrm{~g} / \mathrm{dl}$, and a white cell count of $4,400 / \mathrm{mm}^{3}$ with a normal differential cell count. The erythrocyte sedimentation rate was $8 \mathrm{~mm} / \mathrm{h}$. Urinalysis revealed no proteinuria, but there were many white blood cells in the sediment. Urine culture yielded $10^{7}$ colonies of Escherichia coli per ml. Serum sodium was $139 \mathrm{mEq} / 1$, potassium $3.4 \mathrm{meq} / 1$, and chloride $101 \mathrm{meq} / 1$. Blood urea nitrogen was $10 \mathrm{mg} / \mathrm{dl}$, serum creatinine $0.86 \mathrm{mg} / \mathrm{dl}$, and creatinine clearance $57 \mathrm{ml} / \mathrm{min}$. Serum aspartate aminotransferase (GOT) was $17 \mathrm{IU} / \mathrm{l}$, alanine aminotransferase (GPT) 27IU/1 and lactate dehydrogenase (LDH) $361 \mathrm{IU} / 1$. The thyroid function tests were normal. The values of catecholamines and 17-hydroxycorticoids in the 24-hour urine collection were within normal limits.

The left kidney and ureter were not visible on the intravenous pyelogram, while the right kidney was slightly enlarged $(14 \times 7 \mathrm{~cm})$ with normal calices, pelvis, and ureter. X-ray computed tomography demonstrated that the left kidney was contracted with cystic structures surrounded by calcification, and that no abnormalities were found in the right kidney. The left renal artery was not visualized by angiography, and the left nephrogram was not revealed even in the late phase. There was no stenosis in the right renal artery. Bilateral renal vein sampling was attempted, but could not be obtained from left renal vein. The renal scintigrams and renograms revealed no accumulation or perfusion of technetium $(\mathrm{Tc})$ $99 \mathrm{~m}$-diethylenetriaminepentaacetic acid (DTPA) in

From the Third Department of Internal Medicine, and * the Second Department of Surgery, School of Medicine, University of the Ryukyus, Okinawa

Received for publication March 1, 1991; Accepted for publication December 9, 1991

Reprint requests should be addressed to Dr. Osahiko Sunagawa, the Third Department of Internal Medicine, School of Medicine, University of the Ryukyus, 207 Uehara, Nishihara-cho, Okinawa 903-01, Japan 
the left kidney.

Although she had a sodium restricted diet $(\mathrm{NaCl}$ $7 \mathrm{~g} /$ day) and bed rest, the blood pressure remained at severe or moderate hypertensive levels $(167 \pm 12 /$ $123 \pm 7 \mathrm{mmHg}$ [mean \pm S.D., $\mathrm{n}=7]$ ), measured daily about 10:00 a.m. for 7 days without antihypertensive medicine (Fig. 1). The drug therapy of a daily dose of $25 \mathrm{mg}$ captopril was started. However the blood pressure remained hypertensive levels. The daily dose of captopril was increased to $37.5 \mathrm{mg}$, and indapamide at a dose of $1 \mathrm{mg}$ daily was added to the antihypertensive therapy. This combination drug therapy then decreased her blood pressure to $137 \pm 7 / 95 \pm 4 \mathrm{mmHg} \quad(\mathrm{n}=7)$, measured daily for a week.

An unilateral nephrectomy was performed because the causes of hypertension and the repeated urinary tract infection were thought to be possibly related to an

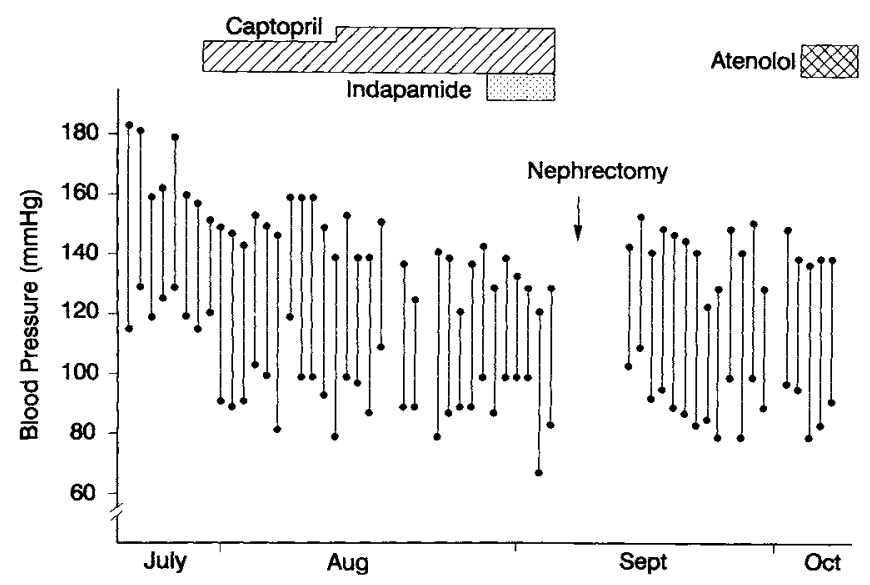

Fig. 1. Systolic and diastolic blood pressure before and after the surgery. The moderate or severe hypertension was controlled with captopril and indapamide before the nephrectomy. Although the blood pressure was reduced after the nephrectomy, an antihypertensive agent was necessary to restore the blood pressure to normotensive levels.

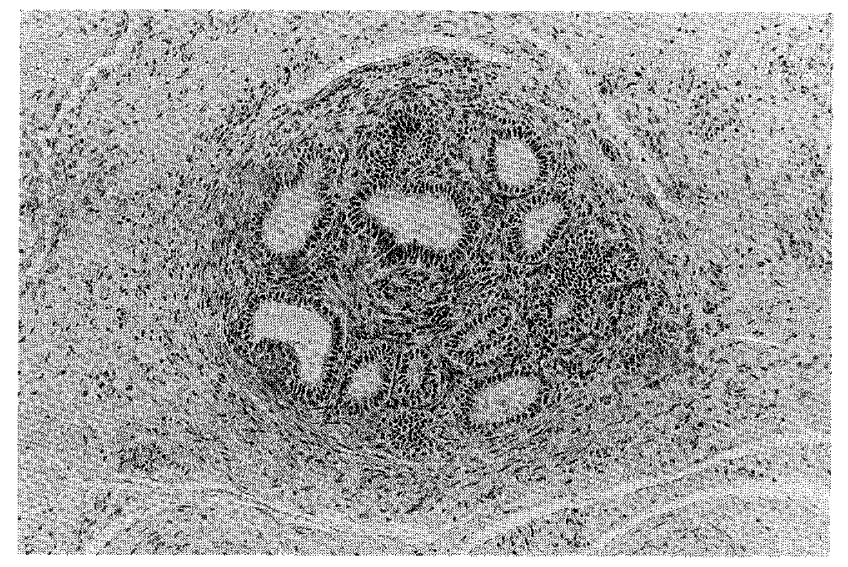

Fig. 2. Photomicrograph of the removed kidney, showing primitive ducts with abundant mesenchymal strumae. There were no mature intact nephrons $(\times 400)$. abnormality in the left kidney. The removed kidney had an irregular and cystic appearance, and was atrophic with a size of $7 \times 3 \times 1.5 \mathrm{~cm}$. As shown in Fig. 2, the histological examination revealed primitive ducts encompassed by abundant mesenchymal strumae, and the absence of matured nephrons. In a few areas clusters of irregular cysts with cuboid epithelium were observed. These findings were well compatible with those of renal dysplasia $(1,2)$. Neither hyperplasia of the juxtaglomerular apparatus nor findings of pyelonephritis were demonstrated in the histology of the removed kidney. After the nephrectomy, her blood pressure was $145 \pm 11$ $190 \pm 10 \mathrm{mmHg}(\mathrm{n}=7)$ without any antihypertensive agents. Plasma renin activity (PRA) and plasma aldosterone concentration (PAC) were measured in blood sampling at 8:00 a.m. with complete bed rest in supine position for more than one hour; PRA before and after the nephrectomy were 3.68 and $4.46 \mathrm{ng} / \mathrm{ml} / \mathrm{h}$, respectively, and PAC 18.2 and $15.0 \mathrm{ng} / \mathrm{dl}$, respectively.

The patient was readmitted 6 months later for evaluation of postoperative state. No deterioration of her renal function was found. The blood pressures were $(144 \pm 4 / 93 \pm 4 \mathrm{mmHg}, \mathrm{n}=7)$ measured for one week under no administration of antihypertensive agents. PRA was $3.97 \mathrm{ng} / \mathrm{ml} / \mathrm{h}$ and PAC $18.4 \mathrm{ng} / \mathrm{dl}$.

\section{Comments}

Unilaterally small kidneys is a relatively common finding in adults (7). Most of the small kidneys, however, are abnormal only in size. The differential diagnosis of unilateral small kidneys includes unilateral renal hypoplasia, segmental hypoplasia, and renal dysplasia. Renal hypoplasia is defined as a reduction in the number of nephrons resulting in a small kidney of normal gross and microscopic appearance. Unilateral segmental hypoplasia with hypertension is known as Ask-Upmark kidney, which has gross and radiographic appearance similar to unilateral renal dysplasia. The problem of distinguishing between hypoplasia and dysplasia is exemplified by Ask-Upmark kidney. Ask-Upmark kidney has a reduced number of lobes and is divided into upper and lower portions by a deep transverse groove. The lesion is regarded as a localized or segmental form of hypoplasia due to insufficient duct branching, whereas a renal dysplasia results from altered structural differentiation of the metanephric components characterized by the presence of primitive ducts, cartilaginous metaplasia, and cortical or medullary cysts $(1,8)$. According to these definitions, the present case might represent the histological appearance of a renal dysplasia rather than a segmental hypoplasia or Ask-Upmark kidney.

The first description of a typical renal dysplasia was made by Cruveilhier in 1836 (3). Subsequently, renal dysplasia has been recognized as the most common etiology of unilateral renal enlargement in neonates 
(9). Since bilateral renal dysplasia is incompatible with survival $(2,3)$, cases with clinical problems which we usually encounter are those with unilateral renal dysplasia. These patients may be classified into two types according to the condition of the opposite kidney; one is with a normal contralateral kidney, and the other with contralateral renal anomalies and association of other congenital defects (2). The contralateral kidney in the present patient was shown to have normal structure and no stenosis of the artery or ureter. Our patient could be classified into the former type.

Malignancy, hypertension, pain, mass effect, and infection are major complications or clinical problems in children with renal dysplasia (6). However, hypertension is not so frequent in adults with unilateral renal dysplasia. According to Ambrose et al, hypertension is present in only 4 out of 27 adult cases with the disease (5). In study by Bloom and Brosman, 15\% of 136 special urologists consider that the development of hypertension is attributable to the dysplastic kidney (3). In contrast, there is the concept that hypertension may be not caused by unilateral renal dysplasia, because the dysplastic kidney lacks a functioning nephron unit, having stenotic or atretic ureters and little renal blood flow (10). Halpern et al have reported an interesting case with hypertension and unilateral renal dysplasia, in whom renal artery stenosis was found in the opposite kidney located in the pelvis (11). The vascular anomalies with unilateral renal dysplasia may be the cause of secondary hypertension. Whether or not a renal dysplasia itself in adults causes the development of hypertension remains unclear.

The cause of hypertension in Ask-Upmark kidney has remains unclear. Although the values of plasma renin activity are inconstant (12), several reports suggest that hyperplasia of the juxtaglomerular apparatus in adjacent normal kidneys with hyperreninemia causes the development of hypertension $(13-15)$. Similarly, elevated renin concentrations and hyperplasia of the juxtaglomerular apparatus have been reported previously in a few patients with renal dysplasia (16). The reninangiotensin-aldosterone system may be related to the etiology of hypertension at least in some cases with renal dysplasia or Ask-Upmark kidney. Although hyperreninemia may contribute to the cause of hypertension in renal dysplasia and Ask-Upmark kidney, there is still a possibility of other etiologies.

Removal of the affected dysplastic kidney failed to reduce blood pressure in 4 adult cases in a previous report (5). The other reports document that normal blood pressure is achieved by the removal of the dysplastic kidney in 3 of 9 cases $(6,10,16,17)$. One is the first adult case with hypertension reported by Bürgler and Hauri (17). The second case deals with a 6-year-old girl with severe hypertension, in whose dysplastic kidney hyperplasia of the juxtaglomerular apparatus is found (16). The third cases is a neonate with severe hyper- tension with an elevation of PRA (10).

In the present patient, the blood pressure decreased significantly after surgery, but not to normal levels in the earlier phase. Widespread arteriolar damage induced by prolonged exposure to high blood pressure may be taken into consideration (18). By resolving widespread arteriolar damage using antihypertensive treatment, the blood pressure may return to normotensive levels. The value of PRA before the surgery was within upper normal limits and PAC was within the normal limits. Both values of PRA and PAC did not change after the surgery. No hyperplasia of the juxtaglomerular apparatus was documented in the histological examination. The findings suggest that renin-angiotensin-aldosterone system may have no causal relationship to hypertension in the present case. She had been normotensive until 25 years of age when urinary tract infection began to occur frequently. Intravenous pyelogram showed no findings of chronic pyelonephritis in the contralateral kidney, and the removal of the affected kidney evidently lowered her blood pressure. Primarily unilateral disease of the kidney is the cause of hypertension in a significant number of patients. Involvement of the renin-angiotensin system could be a factor in all cases, but the detailed mechanisms involved are generally unclear (19). The possibility exists that an unknown pressor substance may be produced in dysplastic kidney and other unilateral renal diseases. Although the exact mechanisms for the development of hypertension in adults are unknown, the dysplastic kidney is suggested to play a role in producing and maintaining hypertension. A dysplastic kidney in an adult may be considered as a cause of secondary hypertension without any relation to the renin-angiotensin system.

Acknowledgments: We are grateful to Dr. Sibley W. Hoobler, Cleveland, Ohio, U.S.A., for his critical reading of the manuscript.

\section{References}

1) Welling LW, Grantham JJ. Cystic and developmental diseases of the kidney. in: The Kidney, 4th Ed, Brenner BM, Rector FC Jr, Eds. Saunders, Philadelphia, 1991.

2) Greene LF, Feinzaig W, Dahlin DC. Multicystic dysplasia of the kidney. J Urol 105: 482, 1971.

3) Bloom DA, Brosman S. The multicystic kidney. J Urol 120: 211, 1978.

4) Marsidi PJ, Lin WI, Pilloff B. Congenital multicystic dysplastic kidney in the adult. Urology 16: 511, 1980.

5) Ambrose SS, Gould RA, Trulack TS, Parrott TS. Unilateral multicystic renal disease in adults. J Urol 128: 366, 1982.

6) Hartman GE, Smolik LM, Shochat SJ. The dilemma of the multicystic dysplastic kidney. Am J Dis Child 140: 925, 1986.

7) Bengtsson C, Hood B. The unilateral small kidney with special reference to the hypoplastic kidney. Review of the litereture and authors' points of view. Int Urol Nephrol 3: 337, 1971.

8) Dein RW, Walker D, Hackett RL. The Ask-Upmark kidney. A case report. Arch Pathol 96: 10, 1973.

9) Koop CE. Abdominal mass in the newborn infant. N Engl J Med 289: 569, 1973. 


\section{Renal Dysplasia with Hypertension}

10) Chen YH, Stapleton FB, Roy S III, Noe HN. Neonatal hypertension from a unilateral multicystic, dysplastic kidney. $\mathrm{J}$ Urol 133: $664,1985$.

11) Halpern NA, Krakoff LR, Haimov M, Strauss L, Gribetz ME, Mitty HA. Renovascular hypertension associated with a pelvic kidney and multicystic dysplasia. J Urol 128: 794, 1982.

12) Godard G, Vallotton MB, Broyer M. Plasma renin activity in segmental hypoplasia of the kidneys with hypertension. Nephron 11: 308, 1973.

13) Meares EM Jr, Gross DM. Hypertension owing to unilateral renal hypoplasia. J Urol 108: 197, 1972.

14) Rosenfeld JB, Cohen L, Garty I, Ben-Bassat M. Unilateral renal hypoplasia with hypertension (Ask-Upmark Kidney). Br Med J 2: $217,1973$.
15) Gilboa N, Bartoletti A, Urizar RE. Severe hypertension in a newborn associated with increased renin production by a hypoplastic kidney. J Urol 128: 570, 1982.

16) Javadpour N, Chelouhy E, Moncada L, Rosenthal IM, Bush IM. Hypertension in a child caused by a multicystic kidney. J Urol 104: $918,1970$.

17) Bürgler W, Hauri D. Vitale Komplikationen bei multizystischer Nierendegenerationen (Multizystischer Dysplasie). Urol Int 38: 251, 1983.

18) Kaplan NM. Clinical Hypertension. Williams \& Wilkins, Baltimore, 1986, p. 321.

19) Wesson LG. Unilateral renal disease and hypertension. Nephron 32: $1,1982$. 